\title{
Comparison of one and two time constant models for lithium ion battery
}

\author{
B. V. Rajanna ${ }^{1}$, Malligunta Kiran Kumar ${ }^{2}$ \\ ${ }_{1,2}$ Department of Electrical and Electronics Engineering, Koneru Lakshmaiah Education Foundation, India
}

\begin{tabular}{l}
\hline \hline Article Info \\
\hline Article history: \\
Received Jul 12, 2019 \\
Revised Sep 30, 2019 \\
Accepted Oct 12, 2019 \\
\hline
\end{tabular}

\section{Keywords:}

Electric vehicle

Energy storage

Equivalent circuit model

Hybrid electric vehicle

Matlab/Simulink

\begin{abstract}
The fast and accurate modeling topologies are very much essential for power train electrification. The importance of thermal effect is very important in any electrochemical systems and must be considered in battery models because temperature factor has highest importance in transport phenomena and chemical kinetics. The dynamic performance of the lithium ion battery is discussed here and a suitable electrical equivalent circuit is developed to study its response for sudden changes in the output. An effective lithium cell simulation model with thermal dependence is presented in this paper. One series resistor, one voltage source and a single $\mathrm{RC}$ block form the proposed equivalent circuit model. The $1 \mathrm{RC}$ and $2 \mathrm{RC}$ Lithium ion battery models are commonly used in the literature are studied and compared. The simulation of Lithium-ion battery 1 RC and 2 RC Models are performed by using Matlab/Simulink Software. The simulation results in his paper shows that Lithium-ion battery $1 \mathrm{RC}$ model has more maximum output error of $0.42 \%$ than $2 \mathrm{RC}$ Lithium-ion battery model in constant current condition and the maximum output error of $1 \mathrm{RC}$ Lithium-ion battery model is $0.18 \%$ more than $2 \mathrm{RC}$ Lithium-ion battery model in UDDS Cycle condition. The simulation results also show that in both simple and complex discharging modes, the error in output is much improved in $2 \mathrm{RC}$ lithium ion battery model when compared to 1 RC Lithium-ion battery model. Thus the paper shows for general applications like in portable electronic design like laptops, Lithium-ion battery $1 \mathrm{RC}$ model is the preferred choice and for automotive and space design applications, Lithium-ion $2 \mathrm{RC}$ model is the preferred choice. In this paper, these simulation results for $1 \mathrm{RC}$ and 2 RC Lithium-ion battery models will be very much useful in the application of practical Lithium-ion battery management systems for electric vehicle applications.
\end{abstract}

Copyright $(2020$ Institute of Advanced Engineering and Science. All rights reserved.

\section{Corresponding Author:}

B. V. Rajanna,

Department of Electrical and Electronics Engineering,

Koneru Lakshmaiah Education Foundation,

Green Fields, Vaddeswaram, Guntur-522502, Andhra Pradesh, India.

Email: bv.rajanna@gmail.com

\section{NOMENCLATURE}

Urban Dynamometer Driving Schedule (UDDS)

Lithium-ion battery $(\mathrm{LiB})$

BMS battery management system

$C_{Q}$ is capacity of cell (Ah)

$C_{T}$ is capacity of heat $\left(\mathrm{Jm}^{-3} \mathrm{~K}^{-1}\right)$

$V_{o c}$ is the open circuit voltage $(\mathrm{V})$

$R_{0}$ is the Ohmic resistance $(\Omega)$ 
$R_{1}, R_{2}$ are the polarization resistances $(\Omega)$

$C_{1}, C_{2}$ are the polarization capacitances $(\mathrm{F})$

$V_{t}$ is the terminal voltage of the battery $(\mathrm{V})$

ECM stands for Equivalent Circuit Model

EKF stands for Extended Kalman Filter

$I$ is the current drawn by the load (A)

NMC stands for Nickel-Manganese-Cobalt

OCV sands for Open Circuit Voltage (V)

$P_{S}$ is cell power dissipation (W)

$Q_{e}$ is the charge drawn out from the cell (Ah)

$R_{T}$ is resistance due to convection $\left(W^{1} m^{-2} K^{-1}\right)$

$S$ is the Laplace transform variable

$\mathrm{SOC}$ is the state of charge

$T$ is the cell internal temperature $\left({ }^{\circ} \mathrm{C}\right)$

$T_{a}$ is the ambient temperature $\left({ }^{\circ} \mathrm{C}\right)$

\section{INTRODUCTION}

An Electric Vehicle (EV) has the less driving range and its precise forecast is very important. The drivers must know how far the vehicle would travel and when to recharge the battery. The prediction of battery performance by battery management system is very essential and the battery need to be replaced whenever needed. It is very important to utilize the full performance capability of battery and thus the precise calculation of remaining charge of battery is necessary. Just like the fuel gauge of conventional vehicle, the individual battery or battery packs has the state of charge (SOC).

The cell balancing is very essential in lithium ion battery packs in vehicles with electrified power trains to avoid thermal runaway and thus accurate SOC estimation and run time calculation of battery must be needed for battery pack cell balancing by BMS. The vehicle under all operating conditions must need accurate estimation of SOC, cell ageing, different discharge current rates and account for changes in temperature. The cell ageing in battery is increased by wide ranging operation of SOC, demanding profiles of load and increase in temperature.

The precise estimation of SOC of battery is done by simple technique known as Coulomb counting. The coulomb counting technique has the drawback which does not include parasitic reactions or self discharge currents in the cell and depends on the cell current flowing into external circuits. The periodic recalibration is necessary for correcting errors in current measurement which accumulate with time. The various factors such as cycle-age, inner cell temperature, average discharge current and storage time (self-discharge) are responsible for capacity of maximum charge contained in a cell. The battery numerical analysis is most commonly done by ECM. The common choice of modeling lithium ion cells is having no parasitic branch. It consists of one or two $R C$ blocks [1-3].

The modeling of lithium ion cells is simple in computation analysis. The extended Kalman filter (EKF) technique can also be used in this modeling [3-5]. A novel, simple and sensitive model of lithium cell is described here. The general equivalent circuit model has $n R C$ blocks which can be minimized into ECM with just a single $R C$ block with $\mathrm{n}=1$ which is sufficient to capture all dynamic characteristics of a lithium cell such as cell inner temperature, average discharge current and non-linear open circuit voltage [6-25]. A suitable pulse discharge current tests were conducted on NMC cells under different working conditions and dynamic parametric estimation of data is collected. This dynamic data of cell is used to compare with the simulation result of equivalent circuit elements of model using Simscape, Simulink and MATLAB. The looks up tables are used to define the values of elements in equivalent circuit which are reliant on Temperature and SOC in a parameter estimation procedure [26-38]. The experimental dynamic data of lithium cell is used for general simulation purposes. The run-time calculation and SOC estimation of battery can be done by this process.

The paper is organized as follows: Section 2 explains the basic chemical reaction equations for Lithium ion battery charging and discharging process. Section 3 describes the development of simple dynamic electrical circuit model. Section 4 deals with the experimental setup. Section 5 describes the modeling and simulation in which the results of the dynamic data of cell are compared with the results of electrical equivalent circuit modeling of cell. Section 6 gives conclusion in which the description of work summary and work to be done in future are explained. 


\section{CHARGING AND DISCHARGING PROCESS OF LITHIUM ION BATTERY}

Assuming that the two new electrodes Lithiated carbon $\left(\mathrm{Li}_{x} C_{6}\right)$ and the Lithium Cobalt Oxide $\left(\mathrm{Li}_{1-x} \mathrm{CoO}_{2}\right)$ are placed in electrolyte solution. The following chemical reactions take place between the electrodes and electrolyte solution LIPF $_{6}$-EC-DMC (Lithium hexafluoro phosphate-Ethylene CarbonateDimethyl Carbonate) as shown below during charging and discharging process of a lithium-ion cell. A lithium metal is not contained in lithium-ion battery ( $\mathrm{LiB})$ but has only $L i^{+}$ions. These ions move from one electrode to another in electrolyte solution. The electrolyte solution is an electronic insulator and good ionic conductor. The process of charge and discharge for a lithium ion battery is shown in Figure 1.

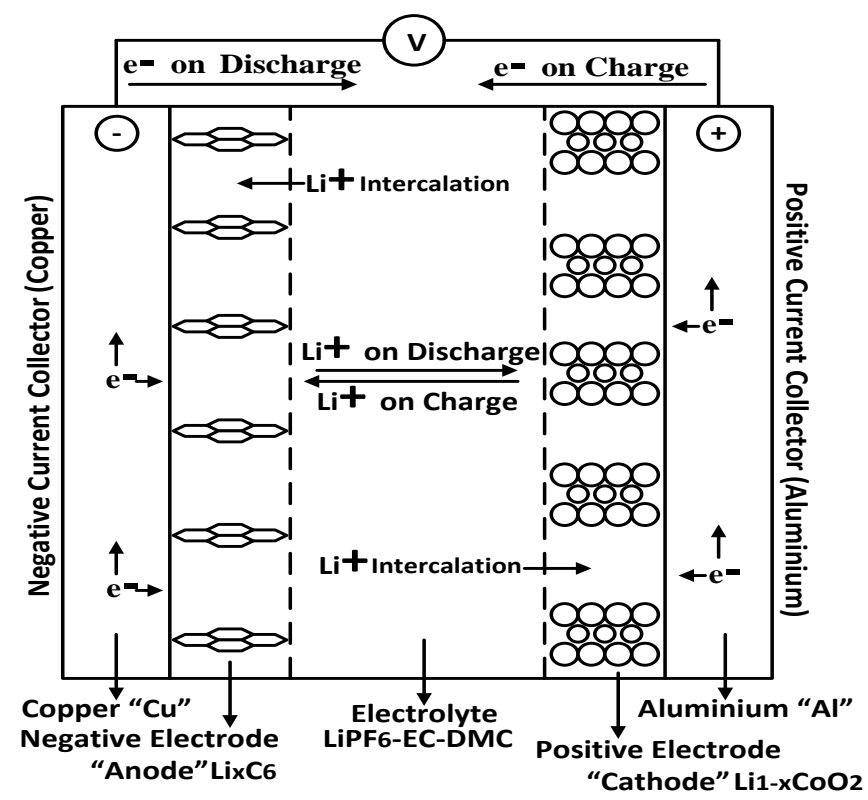

Figure 1. Schematic of lithium-ion cell showing charge and discharge process

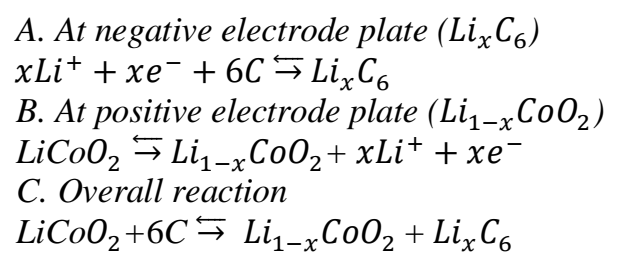

In the above chemical equations, the process of discharge is associated with the upper arrow and the process of charge is associated with lower arrow. The electrolyte solution in lithium ion battery is formed by dissolving organic solvent called EC-DMC (Ethylene carbonate or Di-methyl Carbonate) in inorganic solvent called LIPF $_{6}$ (Lithium Hexa Fluro Phosphate). The whole lithium ion battery electrochemical chain is represented as $\mathrm{Li}_{1-x} \mathrm{CoO}_{2} / \mathrm{LIPF}_{6}-\mathrm{EC}-\mathrm{DMC} / \mathrm{Li}_{x} \mathrm{C}_{6}$. A low potential is seen in discharge state of a new cell. The positive electrode $\left(\mathrm{LiCoO}_{2}\right)$ contains full of $\mathrm{Li}^{+}$ions and negative electrode is empty (carbon $\mathrm{C}$ ) during the initial state of a cell. The exchange of ions and electrons takes place in lithium ion battery during electrochemical reaction which is a redox process. $\mathrm{Li}^{+}$ions from anode (positive electrode) move towards the cathode (negative electrode) during the charge process. During charge process, the positive electrode $\left(\mathrm{Li}_{1-x} \mathrm{CoO}_{2}\right)$ loses electrons (oxidation) and the negative electrode $\left(\mathrm{Li}_{x} \mathrm{C}_{6}\right)$ gains electrons (reduction) and thus the electron flow in the external circuit is from cathode to anode. $\mathrm{Li}^{+}$ions from anode (negative electrode) move towards the cathode (positive electrode) during the discharge process. During discharge process, the negative electrode $\left(\mathrm{Li}_{x} \mathrm{C}_{6}\right)$ loses electrons (oxidation) and the positive electrode $\left(\mathrm{Li}_{1-x} \mathrm{CoO}_{2}\right)$ gains electrons (reduction) and thus the electron flow is from anode to cathode in the external circuit. Chemical reactions of a lithium ion battery during charge and discharge are shown above in $A$ and $B$. The overall battery reaction as shown in $C$. 


\section{LITHIUM ION BATTERY ECM}

To simulate and characterize lithium-ion cells, researchers have developed number of equivalent circuit models in the past. An electrochemical model is time-consuming, rigorous in computation analysis and not suitable and comfortable for run-time applications or system-level modeling but can be able to simulate the internal lithium cell dynamics [10-15]. Thus, Equivalent circuit models (ECM) is an alternative approach and replacing electrochemical models. The parameter values of circuit elements of an equivalent circuit model can be compared with the physical process of data in a cell. The level of difficulty is determined as an exchange between the computational effort and reliability. The nonlinear electrochemical phenomenon inside the battery is captured by these models and thus avoids the complex lengthy calculations of electrochemical process. These models are especially used in power train electrification for system-level modeling. The thermal effects were not shown by most of the models in present literature. The values of elements in the circuit are defined by the look-up tables to avoid the limitation of existing models considering temperature variable separately. The $1 \mathrm{RC}$ and 2 RC Equivalent Circuit models are shown in Figure 2 (a) and Figure 2 (b) where Voc represents the lithium ion battery open circuit voltage that is controllable and generally varies non-linearly with SOC, Ro represents the lithium ion battery ohmic resistance that shows the electrolyte solution resistance and battery contact resistance, $R_{1}$ and $R_{2}$ represents the resistances of polarization, $C_{1}$ and $C_{2}$ represents the polarization capacitances, $I$ represents the load current that is measured directly by the sensor of current and finally $V_{t}$ represents the battery terminal voltage that is measured directly by the sensor of voltage.

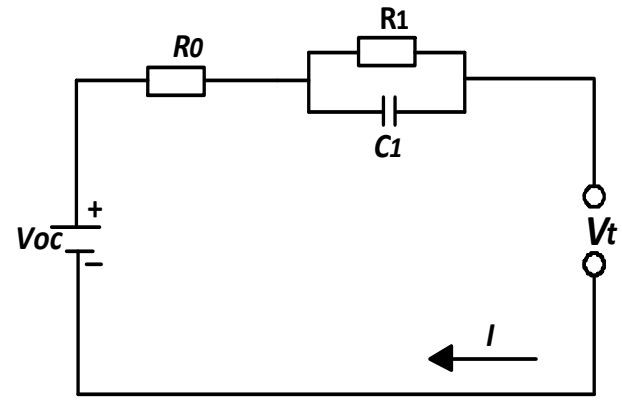

(a)

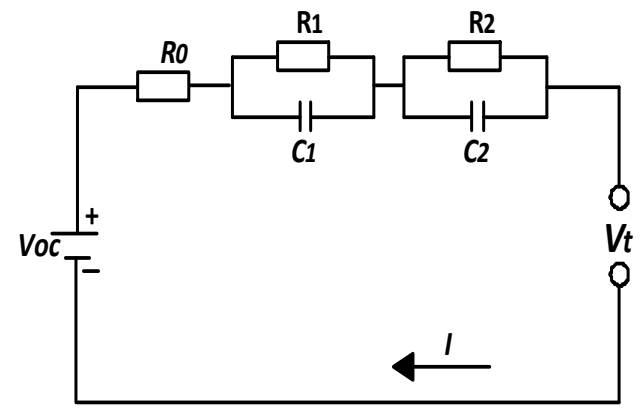

(b)

Figure 2. Equivalent circuit model;

(a) $1 \mathrm{RC}$ equivalent circuit model, (b) 2 RC equivalent circuit model

The number of circuit elements in an equivalent circuit model decides the exchange between complexity and reliability. The exchange between the reliability and complexity is decided by the choice of the model structure to fit equivalent circuit complexity and experimental data. Experimental data sets can be well fitted by an extremely complex equivalent circuit but cannot be suitable for embedded control applications due to their expensive computation. The availability of computational resources and possibility of direct correlation of parameter values of circuit elements in an equivalent circuit model with the values of physical process of data in a cell must limit model level complexity. An adequate reliability of model can be useful for the purpose of diagnosis due to their direct linking of variation of elements with the physical process of data in a cell. The model accuracy is not improved significantly by increasing number of $R C$ blocks which lead to more computational effort. The characteristics of a cell decide the number of $R C$ blocks ranging from one to three.

For many important industrial problems, a model consisting of one $R C$ block as shown in Figure 2(a) is sufficient and has been adopted in this work but accuracy is a major concern for capturing the dynamic characteristics of battery and therefore $2 \mathrm{RC}$ battery model as shown in Figure 2 (b) is compared with $1 \mathrm{RC}$ battery model for better precision. The topologies of other equivalent circuit models can also use the estimation techniques presented in this paper. The values of parameters $V o c, R_{0}, R_{1}, R_{2}$ and $C_{1}, C_{2}$ based on temperature and SOC are to be estimated by using the fitting procedure of the cell involves which decides the equivalent circuit model as shown in Figure 2 (a) and Figure 2 (b).

\subsection{Thermal modeling}

Based on SOC and temperature inside a cell, ECM components values are calculated. The cell temperature is maintained as average. The temperature of a cell is solved by (1) and (2): 


$$
\begin{aligned}
& C_{T} \frac{d T}{d t}=-\frac{T-T_{a}}{R_{T}}+P_{S} \\
& T(S)=\frac{P_{S} R_{T}+T_{a}}{1+R_{T} C_{T} S}
\end{aligned}
$$

The representation of variables in (1) and (2) are given in Nomenclature. Combination of cells is required for practical applications instead of an individual cell. The value of temperature in packs of cells is generally different from individual cells and this must be considered in future aspect.

\subsection{Capacity of a cell and its state of charge}

The capacity of a cell based upon the following factors:

- the average discharge current and discharge time in a cell

- the temperature inside a cell

- voltage discharge end value

- time for storage in a cell

- Number of cycles of cell charge and discharge processes.

Average discharge current and discharge time in a cell and the temperature inside a cell are only to be considered for small time periods.

The capacity in a cell is given by (3).

$$
C_{Q}=C_{Q}(I, T)
$$

For a fully charged cell a, the useful charge, $Q_{e}$ is given by (4).

$$
Q_{e}(t)=\int_{0}^{t} I_{m}(\tau) d \tau
$$

The state-of-charge (SOC) inside a cell is given by (5).

$$
S O C=1-Q_{e} / C_{Q}
$$

The representation of variables in (3), (4) and (5) are given in Nomenclature.

\subsection{Estimation of state of charge during runtime}

Coulomb counting is generally used for estimation of SOC during runtime. Periodic error compensation is necessary for coulomb counting since it does not account for voltage charge end value or errors in current measurement. The best method used for the elimination of error is the correlation curve of SOC-OCV [13-15].

\subsection{Parameters of an equivalent circuit model}

The parameters of an equivalent circuit model as shown in Figure 3 are a function of SOC and temperature as shown below:

$$
\begin{aligned}
& R_{0}=R_{0}(S O C, T) \\
& R_{1}=R_{1}(S O C, T) \\
& C_{1}=C_{1}(S O C, T) \\
& V_{o c}=V_{o c}(S O C, T)
\end{aligned}
$$

The representation of variables in (6), (7), (8) and (9) are given in Nomenclature. At different temperatures, the range of discharge experiments was conducted and the parameter estimation procedure is applied to it. Four equivalent circuit elements defined by the results provided in two-dimensional look-up tables.

\section{EXPERIMENTAL SETUP}

At temperatures of $5^{\circ} \mathrm{C}, 20^{\circ} \mathrm{C}$ and $40^{\circ} \mathrm{C}$, effectiveness of model is verified by testing $31 \mathrm{Ah}$ Lithiumion power oriented cells and their system of experiment described in [34]. 


\section{MODELING AND SIMULATION}

The parameter estimation, validation and simulation of proposed equivalent circuit model is done by numerical analysis. The simulated results of an equivalent circuit model are compared with the experimental data during discharge process of a cell and thus estimation of parameter values can be done. By using Simscape blocks and Simscape language, the ECM was created [21]. The representation of equivalent circuit model parameters and its subsystem electrical blocks to calculate the values of circuit elements of an equivalent circuit model is shown in Figure 3.

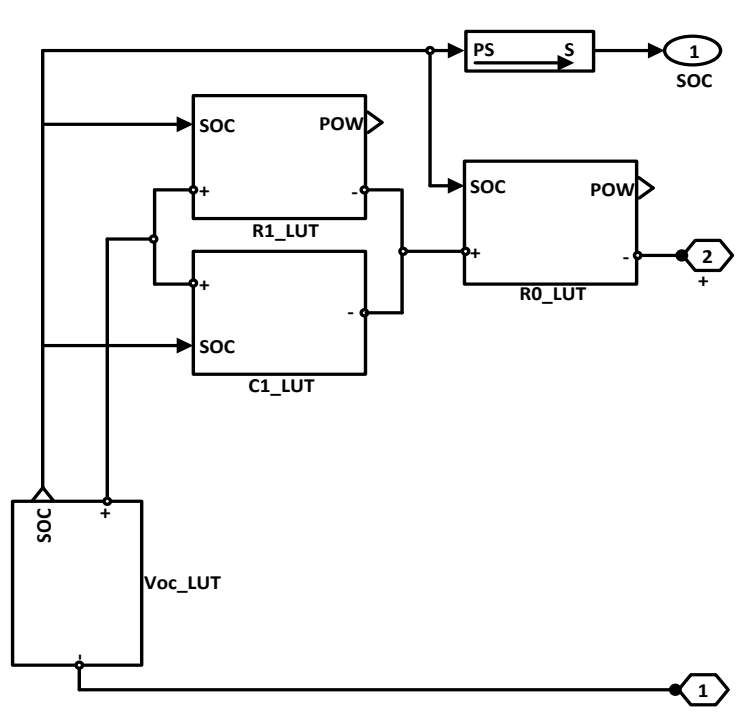

Figure 3. Equivalent circuit model in simscape

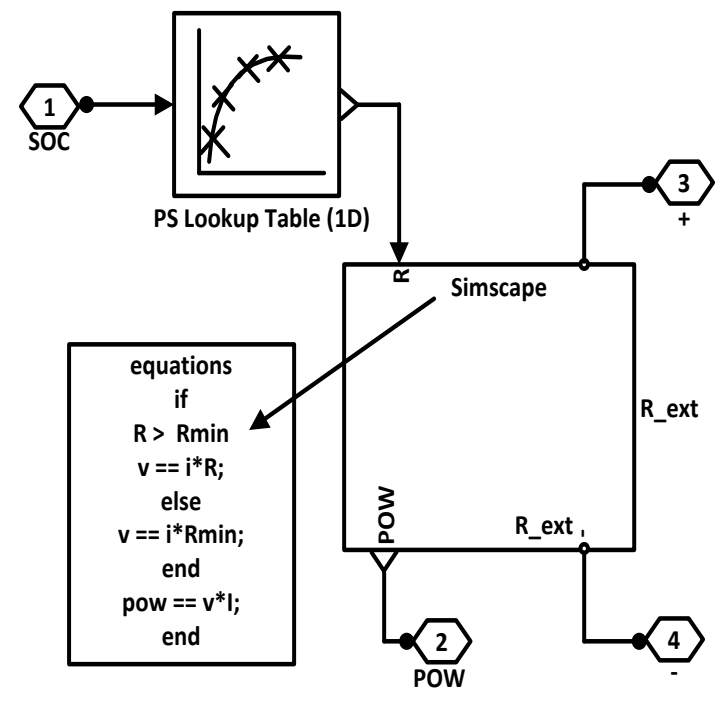

Figure 4. Language code and circuit resistance in simscape

Figure 4 shows the representation of circuit resistance based on Ohm's Law. The real power calculation of circuit resistance is performed for capturing dynamics of temperature in simulation of a cell. The circuit resistance based on SOC and temperature is defined by look up tables. The variation in efficiency of lithium ion cells takes place from cell to cell. The lead-acid batteries mathematical equations as in [13-15] cannot be used for lithium ion chemistry. Parameterization of circuit elements needs lookup tables.

Temperature at each stage is considered separately for parameter estimation. Lookup tables are used for estimation of SOC. The many breakpoints of SOC can be used but can create diminishing advantages. Estimation of parameters can become slow due to more parameter values. The second was that the $10 \%$ SOC have pulses of discharge which provide the good data for parameter near $10 \%$ SOC increments. When unconstrained lookup tables were to be optimized, then more breakpoints may have lot of parameters that were not well defined in the data sets [13-15].

Simulink Design Optimization is used to determine the parameter values with the help of parameter estimation tool. An equivalent circuit charging model consisting of sensor of voltage and source of ideal current is given in Figure 5. The estimation of parameter is done in command line which helps to automate the estimation. With the help of estimation task, the pulse discharge curve for each temperature was run individually. A set of one-dimensional lookup tables versus SOC for the four parameters at each temperature is produced. While comparing the simulation results with experimental data, Simulink Design Optimization iteratively simulated the discharge profile in Simscape to produce these lookup tables. The method of least squares algorithm in nonlinear manner is used. The sum of squared error is minimized by using this algorithm. The parameter estimation steps are shown in the flow diagram of Figure 6. This process is repeated at temperatures of three different stages $\left(5^{\circ} \mathrm{C}, 20^{\circ} \mathrm{C}\right.$ and $\left.40^{\circ} \mathrm{C}\right)$ which results in data consisting of four sets that describe the chemistry of a cell under consideration: $V_{o c}(\mathrm{SOC}, \mathrm{T}), R_{0}(\mathrm{SOC}, \mathrm{T}), R_{1}(\mathrm{SOC}, \mathrm{T})$ and $C_{1}$ (SOC,T). During the simulation stage, by process of interpolation in linear manner, the values of look-up tables in a two-dimensional way are defined which are used to determine the values of circuit elements in ECM. The impedance of a cell does not change because of the magnitude of the discharge current which is an assumption of a resulting model. 


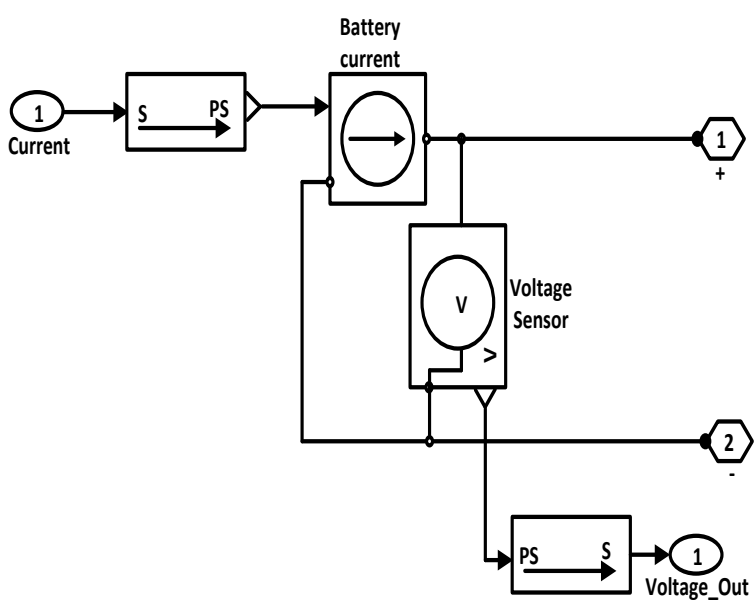

Figure 5. Charging circuit

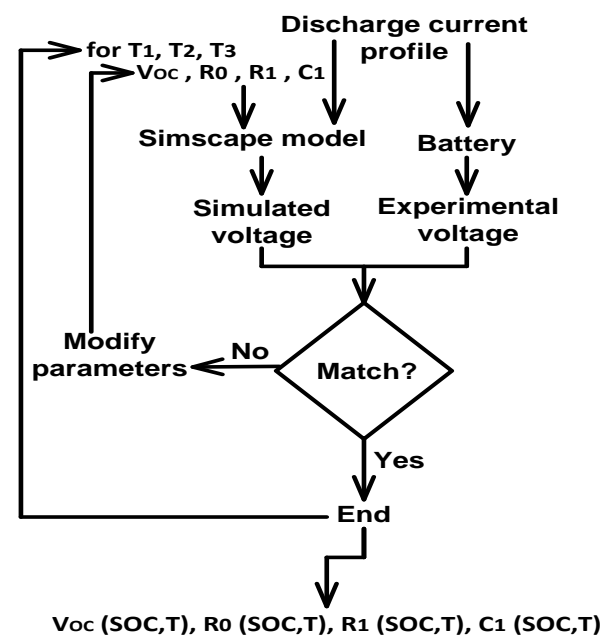

Figure 6. Flow diagram of the parameter estimation procedure

The simulation of an equivalent circuit model effectively captures cell first-order dynamics under test. During the discharge of a cell with a set of pulses of $31 \mathrm{~A}$ at the middle, the cell SOC at bottom decreases with decrease in cell potential at top. The simulation results of Charging /Load Current, Terminal Voltage, SOC and Temperature at $20^{\circ} \mathrm{C}$ for $1 \mathrm{RC}$ and $2 \mathrm{RC}$ equivalent circuit models of Lithium ion battery are shown in Figure 7 and Figure 8. The values of polarization for resistance and capacitance of lithium-ion batteries for RC equivalent circuit models of first-order and second-order are given in Table 1 and Table 2. The output error for RC equivalent circuit models of first-order and second-order for UDDS (Urban Dynamometer Driving Schedule) Cycle are given in Table 3. The maximum errors for the RC equivalent circuit models of first order and second order in constant current mode are $1.64 \%$ and $1.22 \%$. The maximum errors for the RC equivalent circuit models of first order and second order in urban dynamometer driving schedule (UDDS) mode are $1.86 \%$ and $1.68 \%$. This creates a great importance to the application in practical battery management systems for an equivalent circuit model of lithium-ion batteries of electric vehicles.

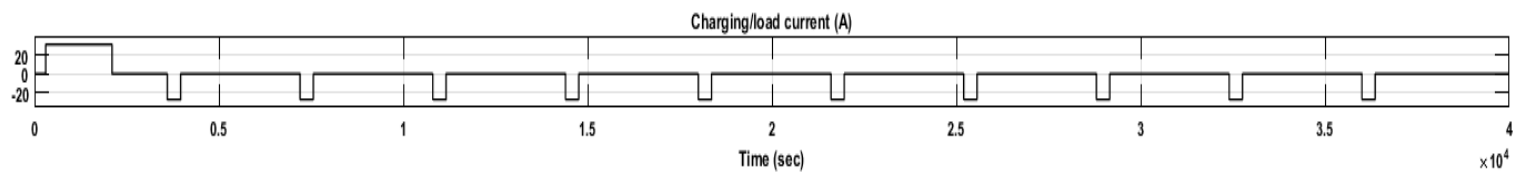

Terminal Voltage (V)

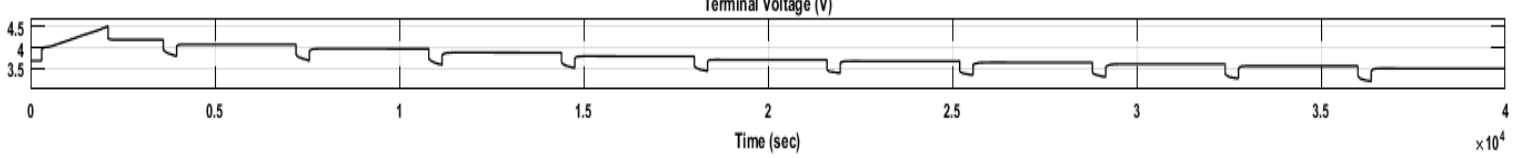

State of Charge (SOC)

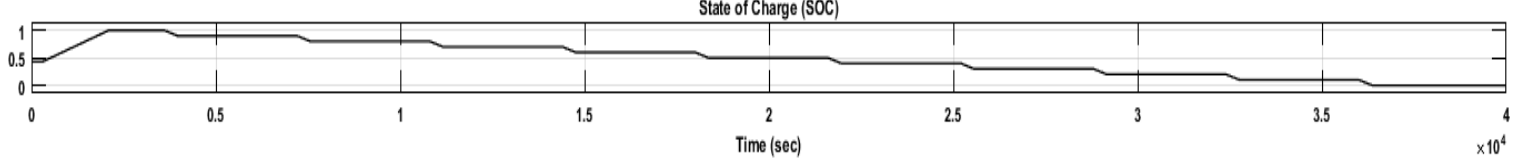

Temperature (degrees C)

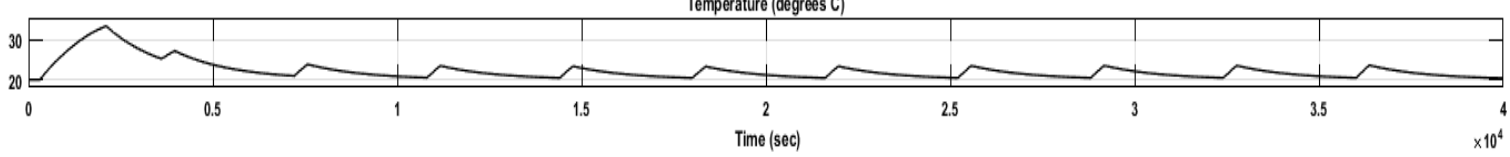

Figure 7. Simulated measurements of 1 RC lithium ion battery model 


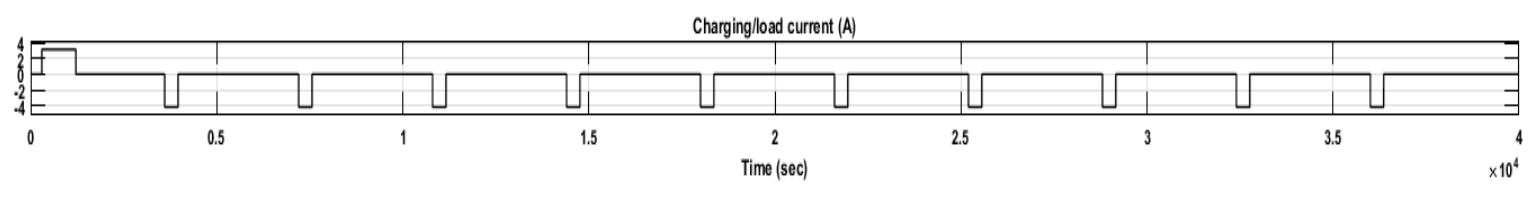

Terminal voltage (V)

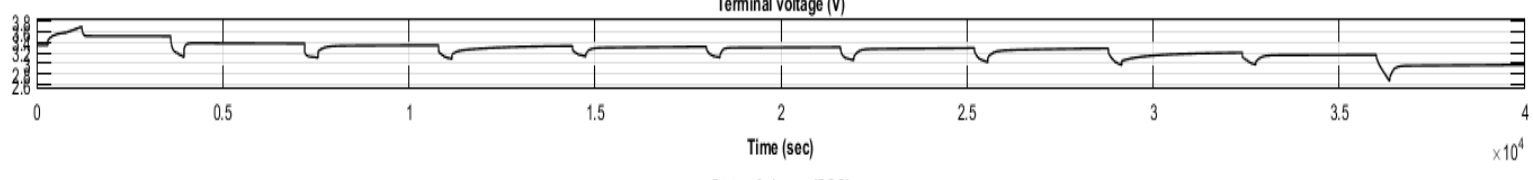

State of charge $(\mathrm{SOC})$

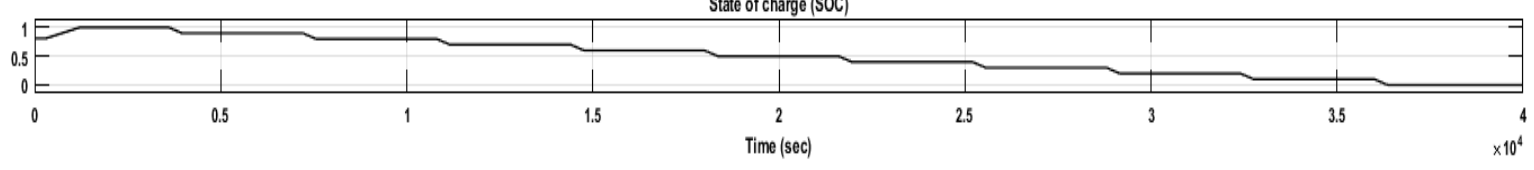

Temperature (degrees $\mathrm{C}$ )

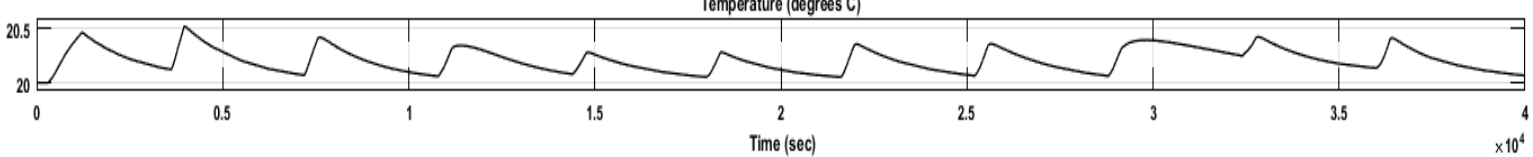

Figure 8 . Simulated measurements of 2 RC lithium ion battery model

Table 1. Polarization values for resistance and capacitance of first-order RC equivalent circuit model for lithium-ion batteries

\begin{tabular}{cccc}
\hline SOC & $\tau_{1} / s$ & $R_{1} / \Omega$ & $C_{1} / 10^{3}$ \\
\hline 0 & 56.2428 & 0.0380 & 1.4741 \\
0.05 & 42.8079 & 0.0260 & 1.6263 \\
0.1 & 51.3872 & 0.0224 & 2.2756 \\
0.15 & 47.5962 & 0.0242 & 1.9489 \\
0.2 & 55.9595 & 0.0235 & 2.3620 \\
0.3 & 34.7824 & 0.0201 & 1.7124 \\
0.4 & 35.8936 & 0.0202 & 1.7610 \\
0.5 & 41.9285 & 0.0209 & 1.9917 \\
0.6 & 37.5655 & 0.0265 & 1.4047 \\
0.7 & 40.6502 & 0.0240 & 1.6796 \\
0.8 & 38.5652 & 0.0270 & 1.4176 \\
0.9 & 37.3132 & 0.0233 & 1.5876 \\
1.0 & 46.2319 & 0.0238 & 1.9285 \\
\hline
\end{tabular}

Table 2. Polarization values for resistance and capacitance of second-order RC equivalent circuit model for lithium-ion batteries

\begin{tabular}{lcrcrcc}
\hline SOC & $\tau_{1} / s$ & $R_{1} / \Omega$ & $C_{1} / 10^{3}$ & $\tau_{2} / s$ & $R_{2} / \Omega$ & $C_{2} / 10^{4}$ \\
\hline 0 & 1.4767 & 0.0332 & 0.0440 & 51.5994 & 0.0167 & 0.3042 \\
0.05 & 5.5739 & 0.0049 & 1.0869 & 62.0730 & 0.0089 & 0.6799 \\
0.1 & 5.2936 & 0.0039 & 1.2879 & 66.0500 & 0.0083 & 0.7802 \\
0.15 & 7.8368 & 0.0041 & 1.8018 & 81.8999 & 0.0077 & 1.0312 \\
0.2 & 5.3761 & 0.0038 & 1.3373 & 69.9299 & 0.0089 & 0.7717 \\
0.3 & 18.7510 & 0.0070 & 2.6149 & 86.1202 & 0.0021 & 3.5082 \\
0.4 & 15.5495 & 0.0043 & 3.4767 & 69.7348 & 0.0046 & 1.4488 \\
0.5 & 2.9831 & 0.0023 & 1.1803 & 45.3307 & 0.0084 & 0.5298 \\
0.6 & 7.1274 & 0.0045 & 1.5088 & 56.7857 & 0.0085 & 0.6498 \\
0.7 & 6.7247 & 0.0050 & 1.2952 & 60.4228 & 0.0100 & 0.5895 \\
0.8 & 4.6402 & 0.0045 & 0.9948 & 47.1252 & 0.0100 & 0.4632 \\
0.9 & 5.3218 & 0.0047 & 1.0817 & 89.7114 & 0.0431 & 0.8194 \\
1.0 & 10.8682 & 0.0041 & 2.5062 & 93.8965 & 0.0068 & 1.3355 \\
\hline
\end{tabular}

Table 3. The error outputs of RC equivalent circuit models of first-order and the second-order for the UDDS cycle

\begin{tabular}{llll}
\hline Type of the RC Equivalent Circuit Model & Absolute Maximum Error (V) & Relative Maximum Error & RMS Error (V) \\
\hline The first-order RC equivalent circuit Model & 0.0694 & $1.86 \%$ & 0.0297 \\
The second-order RC equivalent circuit Model & -0.0627 & $-1.68 \%$ & 0.0281 \\
\hline
\end{tabular}


During cell discharge, reduction in OCV with respect to the nine discharge pulses is reproduced by simulation. The capability of optimizer to capture system dynamics is shown by inset illustration. Equivalent circuit model gives behaviour of cell remarkably well which make it suitable for development of system level models and control algorithms.

Thermal effects are included in isothermally-validated model. The model also includes:

- $\quad$ Exchange of Convective heat between the environment and the cell.

- Heat loss calculation due to internal resistances of cell.

- Calculation of temperature inside a cell.

- $\quad$ The equivalent circuit elements calculation using Two-dimensional look-up tables.

During a constant current discharge, calculation of build-up of temperature is given as example for this model. It shows the temperature build-up.

- Discharge current in a cell: $31 \mathrm{~A}$

- Ambient temperature of a working cell: $20^{\circ} \mathrm{C}$

The temperature build up in constant discharge state is $16^{\circ} \mathrm{C}$.

Simulation involves the parameters of heat which consists of the following:

- Exchange of coefficient of convective heat between the environment and a cell $R_{T}=5 \mathrm{Wm}^{-2} \mathrm{~K}^{-1}$

- Capacity of heat contained in a Cell

$C_{T}=2.04 \times 10^{6} \mathrm{Jm}^{-3} \mathrm{~K}^{-1}$

- Dimensions of a cell: $0.0084 \times 0.215 \times 0.22 \mathrm{~m}^{3}$

Based on the requirements of design or the experimental conditions, the coefficient of convective heat transfer must be fixed.

\section{CONCLUSION}

The cell thermal dynamics is included in the basic equivalent circuit model. Creation of lookup tables with SOC and cell temperature as independent variables is done by estimating the parameters of an equivalent circuit model based on experimental data of discharge pulse. The $1 \mathrm{RC}$ equivalent circuit models is sufficient to capture the cell system dynamics when compared to 2 RC models. The experimental data can be fit better by using techniques of parameter estimation procedure for a higher complexity equivalent circuit model but may be complex when applied to real time. The accuracy of cell voltage is better for $2 \mathrm{RC}$ models. The thermal build-up, generation of heat in the inner cell, SOC of a cell and prediction of cell voltage are included by the model. The modeling of electrochemical systems using equivalent circuits is done by a numerical tool called Simscape and its parameter estimation is done by using Simulink Design Optimization. The development of simple equivalent circuit thermal model for a single-cell is described in this paper. The Simulation for $1 \mathrm{RC}$ and $2 \mathrm{RC}$ Lithium-ion battery equivalent circuit models are performed. The results show that in constant current condition, $1 \mathrm{RC}$ equivalent circuit model has maximum error in output of $1.64 \%$ when compared to $2 \mathrm{RC}$ equivalent circuit models which is $1.22 \%$ and the relative output error difference is $0.42 \%$. The result also show that in UDDS cycle condition, $1 \mathrm{RC}$ equivalent circuit model has maximum output error of $1.86 \%$ when compared to $2 \mathrm{RC}$ equivalent circuit model which is $1.68 \%$ and the relative error difference is $0.18 \%$. From analysis of $1 \mathrm{RC}$ and $2 \mathrm{RC}$ equivalent circuit models, we observe that the $1 \mathrm{RC}$ equivalent circuit model is very much suitable for portable electronic design applications and 2 $\mathrm{RC}$ equivalent circuit model is very much suitable for Automotive and Space design applications. The simulation results of $1 \mathrm{RC}$ and $2 \mathrm{RC}$ equivalent circuit models for lithium-ion battery is very much helpful in practical lithium-ion battery managements systems for electric vehicle applications. These models can only predict the thermal parameters for a single-cell. The cell pack temperature is different from temperature of individual cells. The consideration of this case study is not included in this paper, but will be studied in the future research of this paper. The investigation of parameters dependence on magnitude of current for an equivalent circuit model will be also done in future work.

\section{REFERENCES}

[1] D. Linden, T. B. Reddy, Lead acid batteries, in Handbook of Batteries, 3rd ed., ch, 23, New York, NY: McGraw-Hill, 2002.

[2] J. Appelbaum and R. Weiss, "An electrical model of the lead-acid battery," INTELEC '82 - International Telecommunications Energy Conference, pp. 304-307, 1982.

[3] Z. Salameh, M. Casacca, and W. A. Lynch, "A mathematical model for lead-acid batteries," IEEE Transactions on Energy Conversion, vol. 7, pp. 93-98, Mar. 1992.

[4] M. Casacca and Z. Salameh, "Determination of lead-acid battery capacity via mathematical modeling techniques," IEEE Transactions on Energy Conversion, vol. 7, pp. 442-446, Sep. 1992. 
[5] R. Rynkiewicz, "Discharge and charge modeling of lead acid batteries," in Applied Power Electronics Conference and Exposition, 1999.APEC'99. Fourteenth Annual, IEEE, vol. 2, pp. 707-710, 1999.

[6] Ceraolo, "New dynamical models of lead-acid batteries," IEEE Transactions on Power Systems, IEEE, vol. 15(4), Nov. 2000.

[7] S. Barsali and M. Ceraolo, "Dynamical models of lead-acid batteries: implementation issues," IEEE Transactions on Energy Conversion, vol. 17, pp. 16-23, Mar. 2002.

[8] Cai Chenghui, Du Dong, Ge Jingtian, Liu Zhiyu and Zhang Hua, "Battery-charging model to study transient dynamics of battery at high frequency," TENCON '02. Proceedings. 2002 IEEE Region10 Conference on Computers, Communications, Control and Power Engineering, vol. 3, pp. 1843-1846, 2002.

[9] H. Khafagy and A. Makki, "Mathematical modeling and simulation of lead acid battery," Proceedings International Conference on Information and Communication Technologies: from Theory to Applications, pp. 137, Apr. 2004.

[10] A. Jossen, "Fundamentals of battery dynamics," J. Power Sources, vol. 154(2), pp. 530-538, 2006.

[11] M. Chen and G. A. Rincon-Mora, "Accurate electrical battery model capable of predicting runtime and i-v performance," IEEE transactions on Energy conversion, vol. 21(2), pp. 504-511, 2006.

[12] Jackey, R., "A simple, effective lead-acid battery modeling process for electrical system component selection," $S A E$ Technical Paper 2007-01-0778, 2007.

[13] Olivier Tremblay, Louis-A. Dessaint, and Abdel-Illah Dekkiche, "A generic battery model for the dynamic simulation of hybrid electric vehicles," Vehicle Power and Propulsion IEEE Conference, 2007.

[14] Olivier Tremblay, Louis-A. Dessaint, "Experimental validation of a battery dynamic model for EV applications," EVS24 Stavanger, Norway, May 2009.

[15] XueZhe.Wei, XiaoPeng.Zhao, YongJun.Yuan, "Study of equivalent circuit model for lead-acid batteries in electric vehicle," International Conference on Measuring Technology and Mechatronics Automation, 2009.

[16] W. Peng and Y. Baghzouz, "Accurate circuit model for steady-state and dynamic performance of lead-acid AGM batteries," International Conference \& Utility Exhibition on Power and Energy Systems: Issues and Prospects for Asia (ICUE), Pattaya City, pp. 1-6, 2011.

[17] Peng, Wenxin, "Accurate circuit model for predicting the performance of lead-acid AGM batteries" UNLV Theses, Dissertations, Professional Papers, and Capstones, Paper 1244, 2011.

[18] T. Kim and W. Qiao, "A hybrid battery model capable of capturing dynamic circuit characteristics and nonlinear capacity effects," in IEEE Transactions on Energy Conversion, vol. 26(4), pp.1172-1180, Dec. 2011.

[19] R. Carter, A. Cruden, P. J. Hall and A. S. Zaher, "An improved lead acid battery pack model for use in power simulations of electric vehicles," in IEEE Transactions on Energy Conversion, vol. 27(1), pp. 21-28, Mar. 2012.

[20] Lijun Gao, Shengyi Liu and R. A. Dougal, "Dynamic lithium-ion battery model for system simulation," in IEEE Transactions on Components and Packaging Technologies, vol. 25(3), pp. 495-505, Sep. 2002

[21] A. R. Sparacino, G. F. Reed, R. J. Kerestes, B. M. Grainger and Z. T. Smith, "Survey of battery energy storage systems and modeling techniques," 2012 IEEE Power and Energy Society General Meeting, SanDiego, CA, pp. 1-8, 2012.

[22] M. Shahriari and M. Farrokhi, "Online state-of-health estimation of VRLA batteries using state of charge," in IEEE Transactions on Industrial Electronics, vol. 60(1), pp. 191-202, Jan. 2013.

[23] B. Schweighofer, M. Recheis, T. Gallien, and H.Wegleiter, "Fast and accurate battery model including temperature dependency," in Industrial Electronics Society, IECON 2013 - 39th Annual Conference of the IEEE, pp. 6740-6745, Nov. 2013.

[24] C. Cedric, S. Adnan, A. D. Ahmed and S. M. Muyeen, "Modeling and analysis of battery performance for renewable energy application," 2013 15th European Conference on Power Electronics and Applications (EPE), Lille, pp. 110, 2013.

[25] L. C. Stevanatto, V. J. Brusamarello and S. Tairov, "Parameter identification and analysis of uncertainties in measurements of lead-acid batteries," in IEEE Transactions on Instrumentation and Measurement, vol. 63(4), pp. 761-768, Apr. 2014.

[26] N. Kularatna, "Dynamics and modeling of rechargeable batteries: What electrochemists? Work tells the electronic engineers," in IEEE Power Electronics Magazine, vol. 1(4), pp. 23-33, Dec. 2014.

[27] M. Greenleaf, O. Dalchand, H. Li and J. P. Zheng, "A temperature-dependent study of sealed lead-acid batteries using physical equivalent circuit modeling with impedance spectra derived high current/power correction," in IEEE Transactions on Sustainable Energy,vol. 6(2),pp. 380387, Apr. 2015

[28] N. Akbar, M. Islam, S. S. Ahmed and A. A. Hye, "Dynamic model of battery charging," TENCON 2015 - 2015 IEEE Region 10 Conference, Macao, pp. 1-4, 2015.

[29] E. M. G. Rodrigues, R. Godina, G. J. Osório, J. M. Lujano-Rojas, J. C. O. Matias and J. P. S. Catalão, "Comparison of battery models for energy storage applications on insular grids," 2015 Australasian Universities Power Engineering Conference (AUPEC), Wollongong, NSW, pp. 1-6, 2015.

[30] A. S. Hamedi and A. Rajabi-Ghahnavieh, "Explicit degradation modeling in optimal lead-acid battery use for photovoltaic systems," in IET Generation, Transmission \& Distribution, vol. 10(4), pp. 1098-1106, Oct. 2016.

[31] Y. Cao, R. C. Kroeze and P. T. Krein, "Multi-timescale parametric electrical battery model for use in dynamic electric vehicle simulations," in IEEE Transactions on Transportation Electrification, vol. 2(4), pp. 432-442, Dec. 2016.

[32] C. R. Lashway and O. A. Mohammed, "Adaptive battery management and parameter estimation through physicsbased modeling and experimental verification," in IEEE Transactions on Transportation Electrification, vol. 2(4), pp. 454-464, Dec. 2016. 
[33] T. Huria, M. Ceraolo, J. Gazzarri and R. Jackey, "High fidelity electrical model with thermal dependence for characterization and simulation of high power lithium battery cells," 2012 IEEE International Electric Vehicle Conference, Greenville, SC, pp. 1-8, 2012.

[34] D. Dvorak, T. Bäuml, A. Holzinger and H. Popp, "A comprehensive algorithm for estimating lithium-ion battery parameters from measurements," in IEEE Transactions on Sustainable Energy, vol. 9(2), pp. 771-779, Apr. 2018.

[35] M. Bahramipanah, D. Torregrossa, R. Cherkaoui and M. Paolone, "Enhanced equivalent electrical circuit model of lithium-based batteries accounting for charge redistribution, state-of-health, and temperature effects," in IEEE Transactions on Transportation Electrification, vol. 3(3), pp. 589-599, Sep. 2017.

[36] BV Rajanna, SVNL Lalitha, Ganta Joga Rao, SK Shrivastava, "Solar photovoltaic generators with MPPT and battery storage in microgrids," in International Journal of Power Electronics and Drive Systems (IJPEDS), vol. 7(3), pp. 701-712, Sep. 2016.

[37] X. Lin, "Analytic analysis of the data-dependent estimation accuracy of battery equivalent circuit dynamics," in IEEE Control Systems Letters, vol. 1(2), pp. 304-309, Oct. 2017.

[38] BV Rajanna, Malligunta Kiran Kumar, "Dynamic model development for lead acid storage battery," in Indonesian Journal of Electrical Engineering and Computer Science (IJEECS), vol. 15(2), pp. 609-619, Aug. 2019.

\section{BIOGRAPHIES OF AUTHORS}
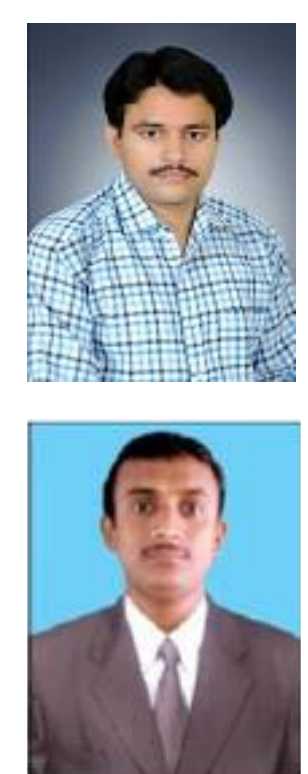

B V Rajanna received B.Tech degree in Electrical and Electronics Engineering from Chirala Engineering College, JNTU, Kakinada, India, in 2010, M.Tech degree in Power Electronics and Drives from Koneru Lakshmaiah Education Foundation, Guntur, India, in 2015 and pursuing full time Ph.D in Electrical and Electronics Engineering at Koneru Lakshmaiah Education Foundation. His Current Research includes, Dynamic Modeling of Batteries for Renewable Energy Storage, Electric vehicles and Portable Electronics Applications, Renewable Energy Sources Integration with Battery Energy Storage Systems (BESS), Smart Metering and Smart Grids, Micro-Grids, AMR (Automatic Meter Reading) devices, GSM/GPRS and PLC (Power Line Carrier) Communication and Various modulation techniques such as QPSK, BPSK, ASK, FSK, OOK and GMSK.

M. Kiran Kumar received B.Tech Degree in Electrical and Electronics Engineering from Gokula Krishna College of Engineering and Technology, JNTU, Hyderabad, India, in 2007, M.E. Degree in Power Electronics and Drives from Sree Sastha Institute of Engineering and Technology, Anna University, Chennai, India, in 2010 and Ph.D in Electrical Engineering at Koneru Lakshmaiah Education Foundation, Guntur, India, in 2016. His research interest includes Switched Reluctance Machines, Power Electronics and Control Systems. 